\title{
Developing pathways for a safer childhood
}

\author{
Asvini D Fernando ${ }^{1}$ \\ Sri Lanka Journal of Child Health, 2012; 41(1): 3-8
}

(Key words: Pathways for development child abuse and neglect; child protection)

Chief guest, Hon. Shiranee Tilakawardene, Judge of the Supreme Court of the Democratic Socialist Republic of Sri Lanka, Professor Deepthi Samarage immediate Past President, Dr. Anuruddha Padeniya Honorary Secretary, Past Presidents, members of the Council, members of the College, distinguished invitees, ladies and gentlemen,

It is with great pride, mixed with humility that I take over as the $15^{\text {th }}$ President of the Sri Lanka College of Paediatricians. I applaud the outgoing president Professor Deepthi Samarage and her Council for a job well done. I welcome and congratulate the members of the new Council. I invite all members of the College to participate actively in College activities. It is each and every one of you that constitutes the College.

The Sri Lanka Paediatric Association, originally formed in 1953, progressed to become the Sri Lanka College of Paediatricians (SLCP) in 1996. The SLCP is the academic body for child health care in Sri Lanka. This includes continuing professional development as well as formulation of guidelines and postgraduate activities. In addition, the SLCP helps to refine important statutory provisions on child health issues and advises the Ministry of Health of the Government of Sri Lanka on all aspects of child health. Hence, the enormity of the task undertaken by me is daunting! However, with the support of an able Council, I feel we will be able to achieve our goals in the year ahead. I am pleased to offer my pledge to take this august body to greater heights. The theme I have chosen for my Presidential Year is developing pathways for a safer childhoodô I have chosen three pathways for development:

1. Creating safe communities for children

2. Rational management of infectious diseases

\footnotetext{
${ }^{1}$ Associate Professor in Paediatrics, Faculty of Medicine, University of Kelaniya

*Address delivered on induction as President SLCP, November 2011
}

\section{Optimizing childhood nutrition}

The logo I have developed portrays the 3 pathways for development.

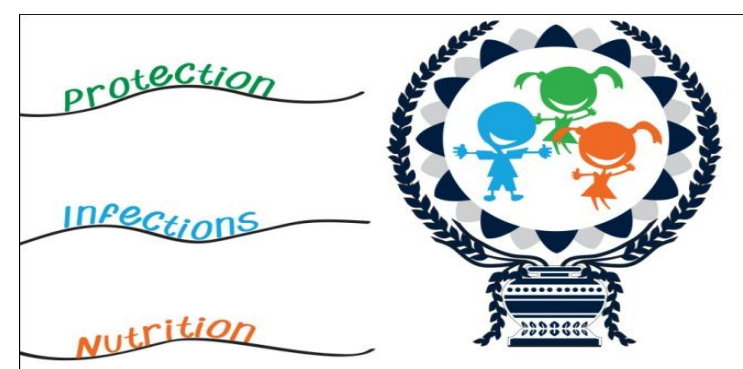

Figure 1: Logo

The 3 children being encircled by 24 lotus petals depicts the 24 hour services provided by the paediatricians for the children of Sri Lanka. The lotus petals are an adaptation from the logo of the College. Ladies and gentlemen please permit me to talk on pathway number one last as I wish to spend more time on it.

\section{Pathway No. 2: Rational management of infectious diseases}

The history of paediatric infectious diseases closely parallels the history of paediatrics. Early descriptions of childhood illnesses by Greek, Roman and Arabic physicians were of tuberculosis, diphtheria and helminthic infestations. Infectious diseases have been the commonest cause of morbidity and mortality in childhood the world over. Two successful interventions, antibiotics and immunization have led to large strides in reduction of morbidity and mortality. However, the use of these two tools has to be rational.

Improper use of antibiotics has led to the emergence of antibiotic resistance. Lack of clear guidelines, non identification of sensitivity patterns due to poor yields from cultures and haphazard or nonavailability of antibiotics in government hospitals in 
the recent past have, I am sure, added to the emergence of resistance.

The role of the College consists of updating existing antibiotic policies and working closely with the Ministry of Health in an attempt to ensure the availability of antibiotics in paediatric wards throughout the country.

The very successful Expanded Programme of Immunization (EPI) in Sri Lanka has to be protected at all costs. The achievement of very good vital statistics in Sri Lanka, which is the envy of all the neighbours in the region, is due to the hard work of the doctors, nurses, midwives and other paramedical personnel in the country and donor agencies efficiently carrying out and sustaining the EPI programme at a high level. The high maternal literacy rates have helped their endeavours greatly.

We, at the College of Paediatricians, together with the Epidemiology Unit of the Ministry of Health will continue to advise the Government of Sri Lanka on rational changes to the schedule, if deemed necessary, taking into consideration the costs and the need for adding new vaccines into the programme without bowing our heads to commercialism.

\section{Dengue}

Although Sri Lanka has controlled/eliminated a large number of infectious diseases with the successful immunization programme, another infection, dengue haemorrhagic fever (DHF), has raised its ugly head and caused much morbidity and mortality amongst the children of Sri Lanka in the recent past. Last year the College was involved in a major collaborative effort with the Epidemiology Unit of the Ministry of Health in improving the management of DHF. Paediatricians were trained in Thailand. They brought back with them improved fluid management regimens and this has led to improved management of DHF. The College and the Epidemiology Unit conducted several training programmes for doctors and nurses throughout the country and 'National Guidelines on the Management of Dengue Fever and Dengue Haemorrhagic Fever in Children and Adolescents' were published and distributed to all paediatric units. The contributions of Professor Deepthi Samarage, the other paediatricians who received training in Thailand and Drs. J. Weeraman and Hasitha Tissera of the Epidemiology Unit need to be appreciated.

Due to these efforts case fatality rates have seen a decline. The case fatality rates from January to October in the years 2009, 2010 and 2011 have been $0.98 \%, 0.74 \%$ and $0.71 \%$ respectively ${ }^{1}$. There has been a decline in deaths amongst children under 15 years. Case fatality rates of children under 15 year of age as a percentage of all deaths have been $38.1 \%$, $33.7 \%$ and $32.7 \%$, in the years 2009, 2010 and 2011 respectively ${ }^{1}$. There have been 46 deaths in children under 12 years from January to October 2011. The majority $(52 \%)$ of these deaths have occurred within 24 hours of admission to hospital (Figure2).

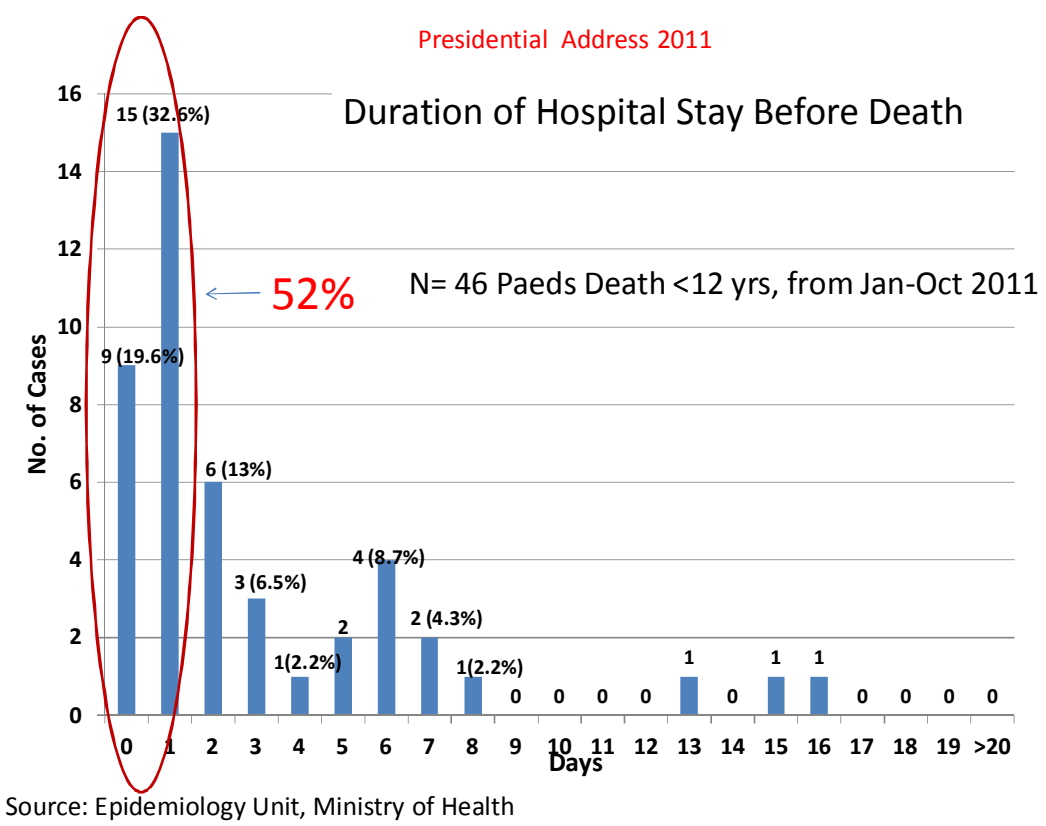

Figure 2: Dengue deaths from January to October 2011 
What more needs to be done to reduce mortality? It is obvious that we need to reduce deaths in the first 24 hours. I see the role of the College (in collaboration with the Epidemiology Unit) as:

- Training of first contact doctors regarding early referral to hospital and educating the general public about early admission to hospital.

- Non-use of non-steroidal anti-inflammatory drugs (NSAIDs) in the management of fever as it is now well documented that the use of NSAIDs leads to increased bleeding in DHF.

- Further improvement in hospital management, with special emphasis on improving the skills of staff in paediatric units in the identification of profound shock, prolonged profound shock and in the appropriate management of these 2 conditions.

It gives me great pleasure to announce that the SLCP has been awarded the honour of hosting the $6^{\text {th }}$ Asian Congress of Paediatric Infectious Diseases in October 2012. Dr. H T Wickramasinghe was responsible for making Sri Lanka a founder member of the Asian Society of Paediatric Infectious Diseases and hence we have been given this opportunity to host the event. The theme chosen for the Congress is: "Rational management of infectious diseases: A path to a safer childhood". Deliberations of this Congress will, I am sure, help Sri Lanka to improve the management of infectious diseases.

\section{Pathway No. 3: Optimizing childhood nutrition}

Malnutrition encompasses under- and over-nutrition. Sri Lanka has been battling with under-nutrition over the years and it still remains a problem. Prevalence of underweight children under 5 years is still $21.6 \%$. There are regional differences within the country as well. High prevalence areas are Nuwara Eliya, the North and the East. If Sri Lanka is to achieve the millennium development goals by 2015, more work needs to be done to reduce the prevalence of underweight children under 5 years of age. The role of the College in this endeavour would be to carry out effective programmes for the promotion of breast feeding, improving the quality and quantity of complementary feeding and improving childhood nutrition.

Poor dietary habits with Westernization of diets, lack of physical exercise, together with unethical advertising of food and drink, have contributed to obesity amongst children in Sri Lanka. Paediatric wards are dealing with Type 2 diabetes and liver diseases as a result. In addition to these problems we know that these children are destined to face problems of hypertension, heart disease and strokes as adults ${ }^{3,4}$. The role of the College in combating over-nutrition consists of:

- the development of an effective programme to deliver the right messages regarding nutrition to parents and children.

- the development of posters and leaflets in collaboration with the Family Health Bureau.

- taking steps to curb unethical advertising to overcome childhood obesity.

\section{Pathway No. 1: Creating safe communities for children}

I have chosen this as the first and most important pathway for development, although I am talking about it last. This is because child abuse and neglect and child protection have been my main areas of interest as a paediatrician. Childhood, I am sure we all agree, should be a carefree period where children play and learn in secure environments, protected and loved by trusted adults who encourage them to achieve their full developmental potential. Unfortunately, ladies and gentlemen we know that this has not been the case and will not always be the case. Child maltreatment or child abuse and neglect is a scourge of children in all geographical regions, ethnic, religious and socio-economic groups the world over. It is said that "Child abuse casts a shadow the length of a life time" (Herbert Ward). The impact of child abuse and neglect does last a life time with an impact on adulthood ${ }^{5,6}$.

As a medical student in the late 70 s and early 80 s I had no sensitization to the problem of child abuse and neglect. My first experience of dealing with these victims was in the United Kingdom in the middle 80s. Then I used to proudly declare that child maltreatment was not a problem in Sri Lanka! Since returning to Sri Lankan soil in 1992, I noted that the victims were there and they were silently beckoning for help. I attempted to establish a hospital based system of management at Teaching Hospitals Karapitiya \& Ragama together with Prof. Harendra de Silva, who went on to become the Chairperson of the National Child Protection Authority. It has been a journey of 19 years fraught with struggles to ensure the rights of these victims, sometimes very lonely, 
emotionally draining and frustrating. Almost all the stakeholders seem to provide at most a knee-jerk response to the problem of the victims. The psychosocial rehabilitation never seemed adequate. There are difficulties in multidisciplinary management amongst probation officers, police and even the medical specialities. There are difficulties in enforcing the law and long delays in the judicial system. In addition, hospital based management is not the ideal with these victims occupying beds in busy paediatric wards. Many countries have gone to community based management systems. The types of abuse in 268 patients managed by me, at $\mathrm{TH}$ Karapitiya and Colombo North Teaching Hospital, Ragama, are depicted in Figure 2:

Presidential Address 2011

\section{Hospital based study}

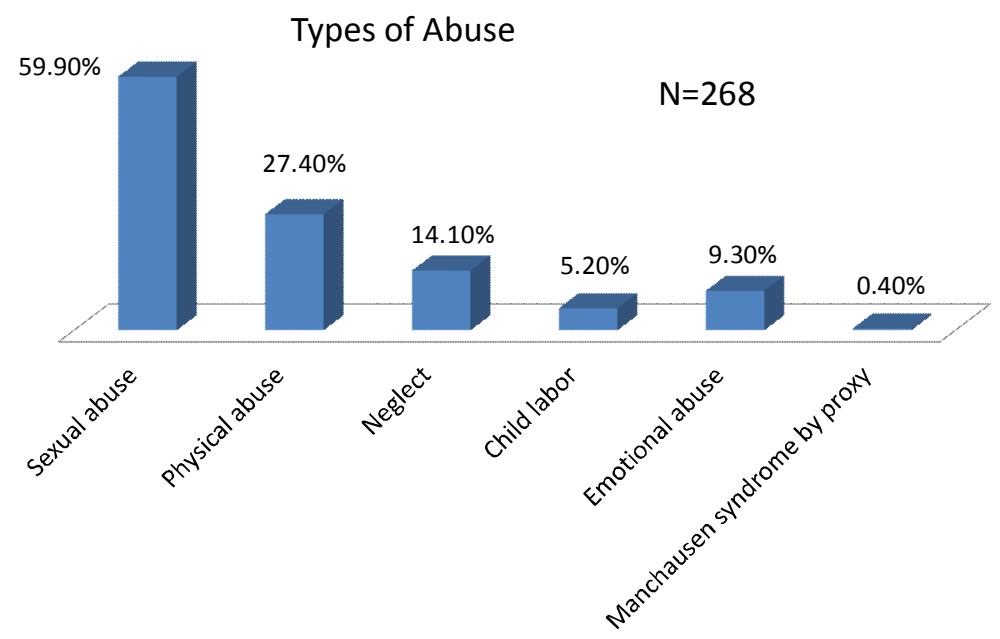

Figure 3: Types of abuse

Sexual abuse was the commonest type of abuse. In $94 \%$ of the victims the perpetrator was a known and trusted adult. The majority $(80.5 \%)$ in this hospital based cohort who were victims of sexual abuse were females. However, a study done amongst University students using the Juvenile Victimization Questionnaire revealed that males (58\%) were more frequently the victims of sexual abuse ${ }^{7}$. Girls are brought for medical attention due to fears of virginity and pregnancy. Boys are probably not brought to hospital as both these are not issues for them. Hence, it is obvious the boys are not receiving the necessary medical or psychological support they should be receiving. This is an issue that needs to be addressed.

Having concentrated on management of victims of abuse for the last 19 years I was tired and weary. The flow of victims never seemed to lessen and the time and energy spent in trying to provide a coordinated approach to management did not, for me, seem to be sufficient for these victims. The formation of the Child Protection Committee of the SLCP last year, of which I am the Chairperson, gave me the opportunity to discuss the problem with like minded individuals.
We felt that we needed to explore a way to prevent this horrible malady rather than tackling it ineffectively when such victims come to us.

ñChild abuse does not go away, but $90 \%$ of child abuse is preventable" (Karen Adams). Based on this premise the child protection committee of the College planned a prevention programme, a óPilot project for the protection of children from abuse, exploitation, violence and neglect'. This is a community based programme titled ñCreating Safe Communities for Childrenò. This project will be carried out by SLCP in collaboration with the Divisional Secretariat, Negombo/Akkaraipattu to establish a community based network through the office of the Divisional Secretary. Other collaborating agencies are the Department of Probation \& Child Care, the Ministry of Health and The Family Health Bureau, the National Child Protection Authority, the Ministry of Education and the Sri Lanka Police - Womenôs \& Children Bureau and the Tourist Police. This project was given a great impetus by the fact that almost all the stakeholders (apart from the Ministry of Education) were represented in an AusAID funded 
programme at the University of Sydney, on prevention of child sexual abuse in Sri Lanka, where I too was invited to participate. At the end of the 2 week programme it was decided that as one of the follow up activities the pilot project planned by the SLCP should be taken forward in collaboration with all the stakeholders.

Strategy of the project is to create safe communities for children to live in. It will be carried out in the Negombo and Akaraipattu $\mathrm{MOH}$ areas and country wide expansion will be based on an evaluation of the pilot project. The objectives of the project are to reduce the incidence of child abuse, exploitation, violence and neglect in a coordinated manner with the participation of all stakeholders through the Divisional Secretariat, to improve the protection of children and to identify effective interventions which promote protection. The programme will utilize field staff already serving the community (midwives, NCPA officers, child rights promotion officers etc). Workshops will be conducted initially to improve the knowledge, attitudes and skills of these workers. These community workers are constantly in touch with families in the community. Home visitation, especially of at risk children has been shown to be an effective way of reducing child abuse and neglect ${ }^{8}$.

In addition, other issues facing children in Sri Lanka like teenage pregnancies, child sex tourism, alcohol and drugs, cigarette smoking and home accidents would be addressed. The incidence, risk factors and protective measures would also be evaluated.

Increasing awareness amongst children and adults of the problem overall, educating society on physical and psychological scars of corporal punishment, training teachers/parents on alternative and effective forms of disciplining children, educating teachers and parents regarding the action to be taken if a child discloses an incident are other activities that are planned.

The Head of Child Protection Programme of Canadian Red Cross Society, Dr. Sinha Wickramasekara has promised to conduct the ñBe Safe Programmeòï a personal safety programme for children aged 5-9 years in the schools in the two pilot areas.

Ladies and gentleman, children are like buds with a potential to bloom into beautiful adults if nature and nurture allows them to attain their full developmental potential. A child abused will die or grow up to be a flawed adult who has not achieved its full developmental potential. The saying that ñThis world is a cruel place not only because of perpetrators of these crimes, but because of those who know of these acts and do nothing about them" is so true in the context of child abuse and neglect. Please let us not be guilty of this crime. A lotus flower grows in mud but blooms beautifully with no mud on it. Some children live in much ómuddiedô environments. Please let us help them to protect themselves and rise above that mud unscathed just like the lotus flower.

\section{Acknowledgements}

On an occasion such as this there are several people who need to be acknowledged. Let me start with 4 members of the Council viz. Drs. BJC Perera and Kalyani Guruge and Professors. Harendra de Silva and Wasantha Karunasekera who have been with me from the time I thought of taking up the Presidency of the College. At a time like this one makes reflections on oneôs life, and appreciates the guidance received during childhood from ones home and school which has led to success. I was very fortunate on both accounts. My school Visakha Vidyalaya gave me a sound overall education. My parents (late Lily Dias Subasinghe, and John William Subasinghe, Presidentsô Counsel) dedicated their lives to ensure that I had a sound education and a safe future and I owe a great deal of gratitude to them. The two men in my life my brother Devinda who has been an ever present source of strength and encouragement and my husband Ranil with whom I have shared the joys as well as the travails of life for the past 26 years have been there to help and guide me whenever I needed them. Finally, I wish to thank all of you for your presence this evening.

\section{References}

1. Personal communication: Dr. J. Weeraman and Dr. Hasitha Tissera Epidemiology Unit of the Ministry of Health. October 2011.

2. MDG Indicators of Sri Lanka. A Mid Term Review - 2008. Department of Census and Statistics.

3. Dietz WH. Overweight in childhood and adolescence. New England Journal of Medicine 2004; 350:855-7. http://dx.doi.org/10.1056/NEJMp048008

4. Centers for Disease Control and Prevention. Childhood obesity facts. Available from: http://www.cdc.gov/healthyyouth/obesity/facts.h tm (Accessed October 2011) 
5. Springer KW, Sheridan J, Kuo D, Carnes M. Long term physical and mental consequences of childhood physical abuse: Results of a large population based sample of men \& women. Child Abuse Neglect 2007; 31(5): 517-30. http://dx.doi.org/10.1016/j.chiabu.2007.01.003

6. Dube SR, Anda RF, Whitfield CL, Brown DW, Felitti VJ, Dong $M$, et al. Long-term consequences of childhood sexual abuse by gender of victim. Am J Prev Med 2005; 28(5):430ï 8.

http://dx.doi.org/10.1016/j.amepre.2005.01.015
7. Fernando AD, Karunasekera KAW. Juvenile victimization in a group of young Sri Lankan adults. Ceylon Medical Journal 2009; 54(3); 804.

http://dx.doi.org/10.4038/cmj.v54i3.1200

8. Donelan-McCall N, Eckenrode J, Olds DL. Home visiting for the prevention of child maltreatment: Lessons learned during the past 20 years. Pediatric Clinics of North America 2009; 56(2):389-403.

http://dx.doi.org/10.1016/j.pcl.2009.01.002 